\title{
Exercise performance in children with asthma: is it different from that of healthy controls?
}

\author{
P. Santuz, E. Baraldi, M. Filippone, F. Zacchello
}

Exercise performance in children with asthma: is it different from that of healthy controls? P. Santuz, E. Baraldi, M. Filippone, F. Zacchello. (CERS Journals Ltd 1997. ABSTRACT: Exercise tolerance and possible limitation in work capacity of asthmatic children is still a matter of debate. The aim of this study was to compare ventilation and gas exchange response to exercise of asthmatic children with that of healthy controls.

Exercise performance was evaluated in 80 children with mild-to-moderate asthma, aged 7-15 yrs, and in 80 healthy controls matched for age, height, weight and habitual level of physical activity. The children performed a maximal exercise test on a treadmill, during which oxygen uptake $\left(V^{\prime} \mathrm{O}_{2}\right)$, carbon dioxide output $\left(V^{\prime} \mathrm{CO}_{2}\right)$ and minute ventilation $\left(V^{\prime} \mathrm{E}\right)$ were measured continuously. No premedication was given to the asthmatic children.

Forced expiratory volume in one second (FEV1) at rest was $93 \pm 11 \%$ of predicted in asthmatic children and $95 \pm 9 \%$ pred in controls. After the run, the mean fall in FEV1 was $13.9 \%$ (range $0-57 \%$ ) and $1.6 \%(0-9 \%)$, respectively $(\mathbf{p}<0.001)$. The two groups achieved similar maximum oxygen uptake $\left(V^{\prime} \mathrm{O}_{2}\right.$, max $)(($ mean $\pm \mathrm{SD}) 40.3 \pm$ 8.4 and $42.6 \pm 9.6 \mathrm{~mL} \cdot \mathrm{min}^{-1} \cdot \mathrm{kg}^{-1}$ in asthmatics and controls, respectively; NS) and maximum minute ventilation output $\left(V^{\prime} \mathrm{E}, \mathrm{max}\right)\left(42.9 \pm 14.8\right.$ and $45.7 \pm 14.9 \mathrm{~L} \cdot \mathrm{min}^{-1} \mathrm{re}-$ spectively; Ns). The kinetics of $V^{\prime} \mathrm{O}_{2}, V^{\prime} \mathrm{CO}_{2}$ and $V^{\prime} \mathrm{E}$ during the test revealed no differences between the two populations. Moreover, anaerobic threshold and oxygen pulse were the same in the two groups. Asthmatics showed a ventilatory pattern with lower respiratory frequencies and greater tidal volumes during the run.

These results suggest that asthmatic children can achieve a level of exercise performance similar to that of healthy children, provided that they have a comparable level of habitual physical activity. The only difference found concerned the ventilatory pattern of the asthmatic children, which was characterized by a reduced respiratory frequency and greater tidal volume at the same minute ventilation. The level of physical conditioning was found to be the main determinant of exercise tolerance for children with controlled asthma.

Eur Respir J 1997; 10: 1254-1260.
University Dept of Pediatrics, School of Medicine, Pulmonary Function Laboratory, Padova, Italy.

Correspondence: E. Baraldi

Dept of Pediatrics

University of Padova

Via Giustiniani 3

35128 Padova

Italy

Keywords: Children

exercise-induced asthma

exercise testing

minute ventilation

pulmonary gas exchange

Received: August 141996

Accepted after revision February 201997
Regular physical activity is generally considered to be an important factor in the growth and development both of healthy children and those affected by chronic diseases, such as bronchial asthma [1]. Despite many studies on exercise performance in asthmatic patients, there are still contradictory data concerning the presence of a limited physical fitness in this population. Impairment of physical performance in asthma has been reported by a number of studies, whilst others have found that work capacity is not reduced [2-5]. Concerns are also raised about exercise capacity and safety in asthmatic children, and particular caution is sometimes advocated for those who wish to attend physical activities or competitive sports [6-10]. On the other hand, it is well known that asthmatic athletes have been able to win Olympic gold medals, and the importance of premedication is generally recognized $[11,12]$.

Recently, emphasis has been placed on a low level of conditioning as the cause of poor endurance fitness in asthmatic subjects $[13,14]$. The lack of agreement in this field has several causes. Firstly, there have been no large studies of asthmatic children, and the results of studies on adult asthma cannot be directly extended to the paediatric age group. Moreover, a different degree of disease severity can affect the physiological response to exertion, causing opposite conclusions when measuring physical fitness in asthma. Finally, a further and more recently recognized pitfall in evaluating exercise performance in asthma $[13,14]$ has been the very different level of conditioning between patients and controls, a factor disregarded in most papers.

Thus, the aims of this study, comparing exercise performance of asthmatic and healthy children, were: 1) to provide data on ventilation and gas exchange response to exercise in a large series of children with mild-tomoderate asthma; 2) to compare asthmatic children and matched healthy controls with the same degree of physical conditioning, thus taking into account the habitual level of physical activity; and 3) to provide an overall evaluation of the exercise performance, considering not 
only maximal values of gas exchange parameters but also the dynamic changes and relationships of these parameters throughout the exercise.

\section{Patients and methods}

\section{Population}

Asthmatic children. Eighty children aged 7-15 yrs, who had suffered from mild-to-moderate perennial asthma for at least $2 \mathrm{yrs}$, volunteered for the study. These children were recruited from the Pediatric Pulmonology/Allergy out-patient clinic of the Department of Pediatrics of Padova, Italy.

A questionnaire was recorded from a medical interview prior to testing, including information about symptoms, presence of atopy, medications, and habitual level of physical activity (HLPA) (see below). The diagnosis and the severity of childhood asthma was defined according to the National Heart Lung and Blood Institute (NHLBI) and World Health Organization (WHO) guidelines [15]. All children suffered from a mild-to-moderate asthma and none reported a limitation in daily life activity. The clinical history was characterized by episodic wheezing and/or breathlessness, with relief of symptoms following inhaled bronchodilators. Skin-prick tests positive for inhaled allergens and laboratory documentation of varying airflow obstruction (both spontaneously and after bronchoprovocation) were present in this group. None of the subjects suffered from clinically apparent respiratory tract infections at the time of the study. They were evaluated during a symptom-free period lasting at least 3 weeks, during which drug regimens were kept unchanged. None were using oral steroids. Regular therapy was discontinued at least $24 \mathrm{~h}$ prior to testing. Children were asked to refrain from physical exercise on the day of the test.

Healthy controls. Eighty healthy children were chosen as a control group. They were recruited from local schools and were matched to the asthmatic children for age, sex, height, weight and HLPA (table 1). The questionnaire

Table 1. - Anthropometric and baseline lung function data for asthmatic and healthy children

\begin{tabular}{lccc}
\hline & $\begin{array}{c}\text { Asthmatics } \\
(\mathrm{n}=80)\end{array}$ & $\begin{array}{c}\text { Controls } \\
(\mathrm{n}=80)\end{array}$ & $\mathrm{p}$-value \\
\hline Sex M/F & $60 / 20$ & $60 / 20$ & \\
Age yrs & $11 \pm 2$ & $11 \pm 2$ & $\mathrm{NS}$ \\
Height cm & $142.9 \pm 11.7$ & $143.2 \pm 11.9$ & $\mathrm{NS}$ \\
Weight kg & $37.4 \pm 9.5$ & $37.8 \pm 9.4$ & $\mathrm{NS}$ \\
HLPA score & $1.75 \pm 0.8$ & $1.74 \pm 0.8$ & $\mathrm{NS}$ \\
FVC \% pred & $100 \pm 11$ & $95 \pm 9$ & 0.03 \\
FEV1 \% pred & $93 \pm 11$ & $95 \pm 9$ & NS \\
FEF25-75 \% pred & $92 \pm 23$ & $110 \pm 19$ & $<0.0001$ \\
Postexercise $\triangle$ FEV1 & $-13.9 \pm 13.8$ & $+1.6 \pm 2.1$ & $<0.0001$ \\
\hline
\end{tabular}

Data are presented as mean \pm SD. M: male; F: female; HLPA habitual level of physical activity; FVC: forced vital capacity; FEV1: forced expiratory volume in one second; FEF25-75: forced expiratory flow between 25 and $75 \%$ of expired vital capacity; $\triangle \mathrm{FEV} 1 \%$ : postexercise percentage fall in FEV1; NS: nonsignificant; $\%$ pred: percentage of predicted value. for HLPA was the same as for the asthmatic group. They had no history or clinical evidence of asthma, atopy and other respiratory disorders.

All subjects were Caucasians. The study was approved by the local Ethics Committee and informed consent was obtained from parents of all children.

\section{Measurements}

Spirometry/electrocardiogram (ECG). Following a medical interview and a physical examination, lung function tests were performed before exercise. Flow-volume curves were obtained by forced expiratory manoeuvres using a $10 \mathrm{~L}$ bell spirometer (Baires ${ }^{\circledR}$; Biomedin, Padova, Italy). The best of at least three forced expirations was accepted. Forced vital capacity (FVC), forced expiratory volume in one second (FEV1) and forced expiratory flow between 25 and $75 \%$ of the expired vital capacity (FEF2575) were measured. These measurements were repeated at the end of running and at 5, 8, 11 and $15 \mathrm{~min}$ after the exercise, or longer as needed. The predicted reference values were those of POLGar and Promadhat [16]. Accuracy of the spirometer was regularly verified with a calibrated syringe. The exercise was performed if the baseline FEV1 of subjects was $\geq 80 \%$ of the predicted value for their height.

The postexercise percentage fall in FEV1 $(\triangle \mathrm{FEV} 1 \%)$ was calculated from the maximal reduction of this parameter recorded at different times after the test. This value was then used to assess the occurrence of exercise-induced asthma (EIA) according to the cut-off value of $15 \%$ [11]. Thus, asthmatic patients were further divided into two subgroups according to the presence or absence of EIA, and named "EIA subgroup" and "No-EIA subgroup", respectively. Prior to exercise, an ECG was recorded at rest (4760 Cardiograph; HewlettPackard, Waltham, MA, USA).

Graded exercise testing. A progressive exercise test was performed on a treadmill (P.K. Morgan, Gillingham, UK). The test was performed under stable environmental conditions (i.e. a temperature of $20-25^{\circ} \mathrm{C}$ and a relative humidity of $60-80 \%)$. After explanation of the test procedure, the children were allowed to familiarize themselves with the treadmill and other instrumentations. The children were then connected to a spirometer and a gas analyser through a fitted mask and a corrugated tube. After a resting period of $3 \mathrm{~min}$ for baseline measurements, the children ran at a treadmill speed of $6.5 \mathrm{~km} \cdot \mathrm{h}^{-1}$, with the inclination being raised by $2 \%$ every minute until a symptom-limited maximum. They were encouraged throughout the test. The fulfilment of at least two of the following three criteria was required to meet the definition of "maximal" exercise test [17]: 1) maximal heart rate (HR,max) close to the theoretical level; 2) stable oxygen uptake $\left(V^{\prime} \mathrm{O}_{2}\right)$ despite increasing workload [18]; and 3) inability of the child to maintain the treadmill speed despite encouragement.

The gas analyser system (Area 1®; Biomedin, Padova, Italy) was calibrated with standard gases (oxygen $12 \%$ and carbon dioxide 5\%) before each test. The system has been described in detail previously $[19,20]$. Briefly, the children breathed through a low resistance, low 
dead space $(40 \mathrm{~mL})$ three-way valve at the mouth and a second emptying valve at the spirometer. The expired gas was collected into a mixing bag, from which samples were taken for the analysis. Respiratory variables were measured by an open-circuit method. Minute ventilation $\left(V^{\prime} \mathrm{E}\right)$ and respiratory frequency $(f \mathrm{R})$ were measured by a $10 \mathrm{~L}$ bell spirometer suitable for fast emptying. The expired gas collected in the mixing chamber was analysed by a paramagnetic oxygen analyser to measure $\mathrm{O}_{2}$ concentration and by an infra-red analyser to measure $\mathrm{CO}_{2}$ concentration. The signals from these devices were processed for determination and display of $V^{\prime} \mathrm{E}$ (corrected to body temperature, atmospheric pressure and saturation with water vapour (BTPS), $\mathrm{L} \cdot \mathrm{min}^{-1}$ ), $V^{\prime} \mathrm{O}_{2}$ (standard temperature and pressure dry (STPD) $\left.\mathrm{mL} \cdot \mathrm{min}^{-1} \cdot \mathrm{kg}^{-1}\right)$, and carbon dioxide production $\left(V^{\prime} \mathrm{CO}_{2}\right)$ (STPD, $\left.\mathrm{mL} \cdot \mathrm{min}^{-1} \cdot \mathrm{kg}^{-1}\right)$. The following parameters of aerobic response to exercise were measured: the maximum oxygen consumption $\left(V^{\prime} \mathrm{O}_{2}, \max \right)$, taken as the highest $V^{\prime} \mathrm{O}_{2}$ achieved during the test; and the anaerobic threshold (AT) $\left(\mathrm{O}_{2} \mathrm{~mL} \cdot \mathrm{min}^{-1} \cdot \mathrm{kg}^{-1}\right)$, identified indirectly at the point where hyperventilation with respect to $V^{\prime} \mathrm{O}_{2}$ occurred, with an increase in the ventilatory equivalent for $V^{\prime} \mathrm{O}_{2}\left(V^{\prime} \mathrm{E} / V^{\prime} \mathrm{O}_{2}\right)$ without a concomitant increase in the ventilatory equivalent for $V^{\prime} \mathrm{CO}_{2}\left(V^{\prime} \mathrm{E} / V^{\prime} \mathrm{CO}_{2}\right)$ as described previously [18, 19].

$\mathrm{O}_{2}$ pulse (HR $\cdot V^{\prime} \mathrm{O}_{2}^{-1} \cdot \mathrm{kg}^{-1}$ ) was calculated at each minute of running. Dyspnoea index ( $\left.V^{\prime} \mathrm{E}, \max / \mathrm{MVV} \%\right)$ was calculated from predicted maximal voluntary ventilation $(\mathrm{MVV})$ as estimated using the formula: FEV $1 \times 35$. This formula has been validated for patients with moderate airway obstruction [18]. HR was monitored by a cardiofrequency meter (Sport Tester ${ }^{\circledR}$ TM PE 3000; Polar Electro, Kempele, Finland).

HLPA questionnaire. A score of HLPA was elaborated from a questionnaire about the type and duration of recreational and sporting activities. Matching the children of the two groups for HLPA was intended to exclude the possible bias of difference in cardiopulmonary fitness due to a different degree of baseline conditioning.

The following score, successfully adopted in a previous study [20], was utilized: 1=sedentary lifestyle (i.e. sedentary unstructured play only); $2=$ regular physical activity (up to $2 \mathrm{~h} \cdot$ week $^{-1}$ ); and $3=$ organized/competitive sport (at least $3 \mathrm{~h} \cdot \mathrm{week}^{-1}$ ).

Data processing. Results are expressed as mean \pm SD. A computer package (Statistica $®$; Microsoft Windows®; Microsoft Corp., Redmond, WA, USA) was utilized for statistical analysis. Unpaired t-tests were used to compare values between the two groups. Analysis of variance (ANOVA, repeated measures) was used to compare the time course of the respiratory variables of the two groups. Linear regression analysis was performed to determine correlations between variables. Results were considered significant at a p-value less than 0.05 .

\section{Results}

\section{Demographics}

The physical characteristics and the baseline pulmonary function of the asthmatic and control subjects are
Table 2. - Drug therapy in the whole asthmatic group, in the EIA subgroup and the No-EIA subgroup

\begin{tabular}{|c|c|c|c|}
\hline & $\begin{array}{l}\text { Whole } \\
\text { group } \\
(\mathrm{n}=80)\end{array}$ & $\begin{array}{c}\text { EIA } \\
\text { subgroup } \\
(\mathrm{n}=27)\end{array}$ & $\begin{array}{c}\text { No-EIA } \\
\text { subgroup } \\
(\mathrm{n}=53)\end{array}$ \\
\hline Inhaled BDP & $39(49)$ & $21(78)$ & $18(34)$ \\
\hline Inhaled DSCG & $27(34)$ & $10(37)$ & $17(32)$ \\
\hline Oral theophylline & 7 (9) & $4(15)$ & $3(6)$ \\
\hline $\begin{array}{l}\text { Others (immunotherapy, } \\
\text { antihistamines etc.) }\end{array}$ & 11 (14) & 4 (15) & 7 (13) \\
\hline No regular treatment & $17(21)$ & $5(18)$ & $12(23)$ \\
\hline
\end{tabular}

Values are presented as absolute number, and percentage in parenthesis. EIA: exercise-induced asthma; BDP: beclomethasone dipropionate; DSCG: disodium cromoglycate.

presented in table 1 . There was no significant difference in the anthropometric data, including HLPA score, between the asthmatic children and healthy controls or between the EIA and No-EIA asthmatic subgroups. According to HLPA score, 39 asthmatic children with score 1,22 with score 2 , and 19 with score 3 were identified and matched to controls. The presence of allergy was demonstrated in 74 out of 80 children $(92 \%)$ by a positive skin-prick test. Dust allergy (i.e. Dermatophagoides pteronyssinus and Dermatophagoides farinae) was present in 70 children, and grass pollen allergy in 24 . Twenty three asthmatic children (29\%) showed multiple allergy. In particular, evidence of atopy was present in $100 \%$ of EIA children and in 47 out of $53(89 \%)$ of No-EIA children.

Drug regimens are detailed in table 2. Overall, $79 \%$ of asthmatic children were on regular therapy. Twenty two out of $27(81 \%)$ EIA patients and 41 out of 53 (77\%) No-EIA patients were on continuous treatment. None of the controls took daily therapy for respiratory or other chronic disorders.

\section{Pulmonary function}

Spirometric data showed normal baseline pulmonary function both in asthmatic and healthy control children (table 1). In asthmatic children, a slightly greater FVC $(100 \pm 11$ vs $95 \pm 9 \%$ pred in controls; $\mathrm{p}<0.05)$ and a lower FEF25-75 were found $(92 \pm 23$ vs $110 \pm 19 \%$ pred in controls; $\mathrm{p}<0.0001)$.

In the asthmatic group, resting spirometric data showed comparable FVC between EIA and No-EIA subgroups, while there was a lower FEV1 $(89 \pm 10 \%$ vs $95 \pm$ $11 \%$ pred; $\mathrm{p}<0.05)$ and $\mathrm{FEF} 25-75(84 \pm 22 \%$ vs $96 \pm 23 \%$ pred; $\mathrm{p}<0.05)$ in the EIA subgroup.

The postexercise lung function showed a significant fall in FEV1 in asthmatic children $(-13.9 \pm 13.8 \%$ with respect to baseline) and a slight increase in FEV1 in controls $(+1.6 \pm 2.1 \%)(\mathrm{p}<0.0001)($ table 1$)$. The $\Delta \mathrm{FEV} 1$ was $30 \pm 11 \%$ for the EIA subgroup and $6 \pm 4 \%$ for the No-EIA subgroup $(\mathrm{p}<0.0001)$. The coefficient of variation of FEV1 for the asthmatic group was $2.9 \pm 1.7 \%$.

\section{Exercise and gas exchange parameters}

No differences were found in baseline metabolic and ventilation values $\left(V^{\prime} \mathrm{O}_{2}, V^{\prime} \mathrm{CO}_{2}, V^{\prime} \mathrm{E}\right)$ between asthmatic 
Table 3. - Maximal cardiorespiratory parameters from exercise testing in asthmatics and controls

\begin{tabular}{lllc}
\hline & Asthmatics & Controls & p-value \\
\hline$V^{\prime} \mathrm{O}_{2}, \operatorname{max~mL} \cdot \mathrm{min}^{-1} \cdot \mathrm{kg}^{-1}$ & $40.3 \pm 8.4$ & $42.6 \pm 9.6$ & $\mathrm{NS}$ \\
$\mathrm{AT} \mathrm{O}_{2} \mathrm{~mL} \cdot \mathrm{min}^{-1} \cdot \mathrm{kg}^{-1}$ & $31.6 \pm 7.3$ & $31.6 \pm 7.3$ & $\mathrm{NS}$ \\
$\mathrm{O}_{2}$ pulse,max mL $\mathrm{mL}^{-1} \cdot \mathrm{kg}^{-1} \cdot \mathrm{beat}^{-1}$ & $0.21 \pm 0.04$ & $0.22 \pm 0.05$ & $\mathrm{NS}$ \\
$V^{\prime} \mathrm{E}, \max \mathrm{L} \cdot \mathrm{min}^{-1}$ & $42.9 \pm 14.8$ & $45.7 \pm 14.9$ & $\mathrm{NS}$ \\
$V^{\prime} \mathrm{E} / \mathrm{MVV} \%$ & $56.7 \pm 9.7$ & $57.5 \pm 9.9$ & $\mathrm{NS}$ \\
$\mathrm{HRmax}$ beats$\cdot \mathrm{min}^{-1}$ & $195 \pm 8$ & $201 \pm 7$ & $<0.0001$ \\
Running time min & $8.2 \pm 2.1$ & $8.6 \pm 2.6$ & $\mathrm{NS}$ \\
\hline
\end{tabular}

Values are expressed as mean $\pm \mathrm{SD} . V^{\prime} \mathrm{O}_{2}$,max: maximal oxygen uptake; AT: anaerobic threshold; $V^{\prime} \mathrm{E}$,max: maximal minute ventilation; $V^{\prime} \mathrm{E} / \mathrm{MVV}$ : dyspnoea index; MVV: maximal voluntary ventilation; HRmax: maximal heart rate; ns: nonsignificant.

and control children. Asthmatic and control children showed substantially similar aerobic and ventilatory capacity when performing a maximal exercise, as indicated by $V^{\prime} \mathrm{O}_{2}$,max, $V^{\prime} \mathrm{E}, \max , V^{\prime} \mathrm{E}, \max / \mathrm{MVV}, \mathrm{AT}$, and $\mathrm{O}_{2}$ pulse,max. The data obtained from maximal exercise testing are listed in table 3.

Within the asthmatic group, no difference was found in the parameters of exercise performance between EIA and No-EIA subgroups. In particular, $V^{\prime} \mathrm{O}_{2}$, max was 40.5 \pm 8.6 and $40.2 \pm 8.4 \mathrm{~mL} \cdot \mathrm{min}^{-1} \cdot \mathrm{kg}^{-1}$ and $V^{\prime} \mathrm{E}$, max was $42.5 \pm$ 14.7 and $43.1 \pm 14.9 \mathrm{~L} \cdot \mathrm{min}^{-1}$, in EIA and No-EIA subgroups, respectively (NS). The comparison between asthmatic and control children in each HLPA subgroup (HLPA 1, 2 and 3) showed similar values of exercise performance (table 4). Parameters of maximal exercise capacity were different only between asthmatic or control subjects of different HLPA subgroups; in particular, aerobic and ventilatory capacity was significantly lower in HLPA 1 and 2 than in HLPA 3 subjects. This means that the exercise performance was related to the level of physical conditioning.

The analysis of submaximal responses of exercise $\left(V^{\prime} \mathrm{O}_{2}\right.$ and $\left.V^{\prime} \mathrm{E}\right)$ confirmed that the exercise performance was very similar for asthmatic and control children. Time course of $V^{\prime} \mathrm{O}_{2}$ and $V^{\prime} \mathrm{E}$ was not different between asthmatics and controls (fig. 1), or between EIA and NoEIA asthmatics. A difference in ventilatory pattern between the asthmatics and controls was identified analysing trends in the values of tidal volume $(V \mathrm{~T})$ and respiratory frequency $(f \mathrm{R})$ during exercise (fig. 2). At comparable workrates, $f \mathrm{R}$ was significantly lower and $V \mathrm{~T}$ was significantly greater in asthmatic children than in controls (ANOVA, $\mathrm{p}<0.001$ and $\mathrm{p}<0.01$, respectively). Thus, asthmatic children were able to achieve the same $V$ 'E throughout the exercise thanks to greater $V$ Ts and lower $f$ Rs. Analysis of ventilatory pattern in EIA and No-EIA subgroups revealed that, during running, $f \mathrm{R}$ was significantly lower in EIA subjects (ANOVA, $\mathrm{p}<0.01$ ) while $V \mathrm{~T}$ was not significantly different between the two populations.
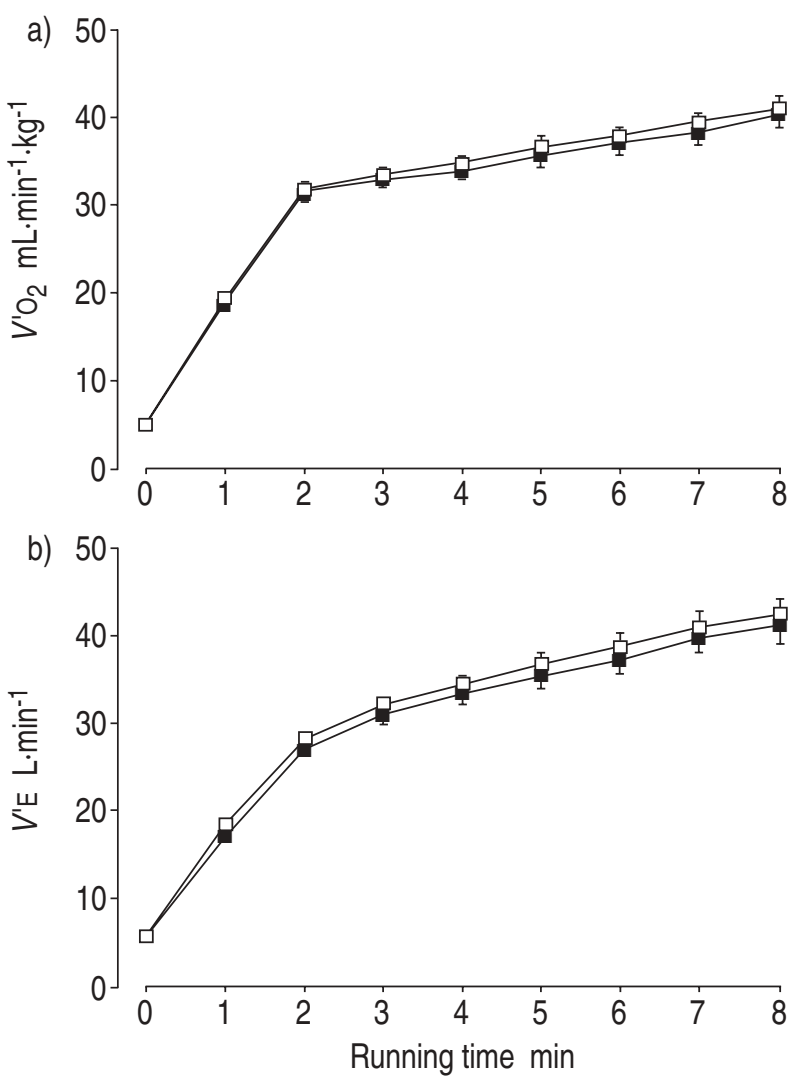

Fig. 1. - a) Oxygen uptake $\left(V^{\prime} \mathrm{O}_{2}\right)$; and b) minute ventilation $\left(V^{\prime} \mathrm{E}\right)$ kinetics during maximal exercise in asthmatic (- - ) and control $(-\square-)$ children. No difference was found between the two groups for either parameter (analysis of variance (ANOVA) $\mathrm{p}=\mathrm{NS}$ ). The data are expressed as mean \pm SEM.

Table 4. - Demographics and maximal exercise parameters for asthmatic and control children of HLPA 1, HLPA 2 and HLPA 3 subgroups

\begin{tabular}{|c|c|c|c|c|c|c|}
\hline & \multicolumn{2}{|c|}{ HLPA 1} & \multicolumn{2}{|c|}{ HLPA 2} & \multicolumn{2}{|c|}{ HLPA 3} \\
\hline & Asthmatics & Controls & Asthmatics & Controls & Asthmatics & Controls \\
\hline Subjects $\mathrm{n}$ & 39 & 39 & 22 & 22 & 19 & 19 \\
\hline Age yrs & $10 \pm 2 * *$ & $10 \pm 2 * *$ & $10 \pm 2 *$ & $10 \pm 2 *$ & $12 \pm 2$ & $12 \pm 2$ \\
\hline FVC \% pred & $101 \pm 11$ & $95 \pm 9$ & $97 \pm 10$ & $94 \pm 8$ & $103 \pm 10$ & $95 \pm 11$ \\
\hline FEV $1 \%$ pred & $94 \pm 11$ & $96 \pm 10$ & $91 \pm 9$ & $95 \pm 8$ & $93 \pm 11$ & $95 \pm 10$ \\
\hline$V^{\prime} \mathrm{O}_{2}, \max \mathrm{mL} \cdot \mathrm{min} \cdot \mathrm{kg}^{-1}$ & $38.5 \pm 7.7 * *$ & $39.3 \pm 7.5^{* *}$ & $39.1 \pm 8.4 *$ & $43.1 \pm 8.5$ & $45.5 \pm 8.4$ & $49.0 \pm 11.4$ \\
\hline AT $\mathrm{O}_{2} \mathrm{~mL} \cdot \mathrm{min}^{-1} \cdot \mathrm{kg}^{-1}$ & $31.3 \pm 8.3$ & $32.1 \pm 7.6$ & $30.9 \pm 6.3$ & $30.1 \pm 6.3$ & $33.1 \pm 6.2$ & $32.4 \pm 8.1$ \\
\hline$V^{\prime} \mathrm{E}, \max \mathrm{L} \cdot \mathrm{min}^{-1}$ & $38.9 \pm 13.4^{* *}$ & $41.3 \pm 12.5^{* *}$ & $42.0 \pm 13.0^{*}$ & $46.1 \pm 13.2$ & $52.2 \pm 16.0$ & $54.4 \pm 18.0$ \\
\hline$V^{\prime} \mathrm{E}, \max / \mathrm{MVV} \%$ & $53.9 \pm 8.6^{* *}$ & $53.4 \pm 9.6^{* *}$ & $58.4 \pm 10.1$ & $58.8 \pm 10.5$ & $60.8 \pm 9.8$ & $60.8 \pm 10.1$ \\
\hline HRmax beats $\cdot \min ^{-1}$ & $194 \pm 8$ & $200 \pm 8$ & $194 \pm 9$ & $202 \pm 6$ & $196 \pm 8$ & $201 \pm 7$ \\
\hline $\mathrm{O}_{2}$ pulse,max $\mathrm{mL}^{-1} \cdot \mathrm{kg}^{-1} \cdot$ beat $^{-1}$ & $0.20 \pm 0.04$ & $0.20 \pm 0.04 * * *$ & $0.20 \pm 0.04$ & $0.21 \pm 0.05 *$ & $0.23 \pm 0.04$ & $0.26 \pm 0.05$ \\
\hline Running time $\min$ & $7.6 \pm 1.6^{* * *}$ & $7.9 \pm 2.2 * * *$ & $7.7 \pm 2.0 * *$ & $8.8 \pm 2.5^{*}$ & $9.8 \pm 2.2$ & $9.8 \pm 3.2$ \\
\hline
\end{tabular}

Values are presented as mean \pm SD. For definitions see legends to tables 1 and 3. Significant differences of HLPA 1 and 2 subgroups with respect to the HLPA 3 subgroup are indicated as follows: *: $\mathrm{p}<0.05 ; * *$ : $<<0.01 ; * * *: \mathrm{p}<0.001$. 

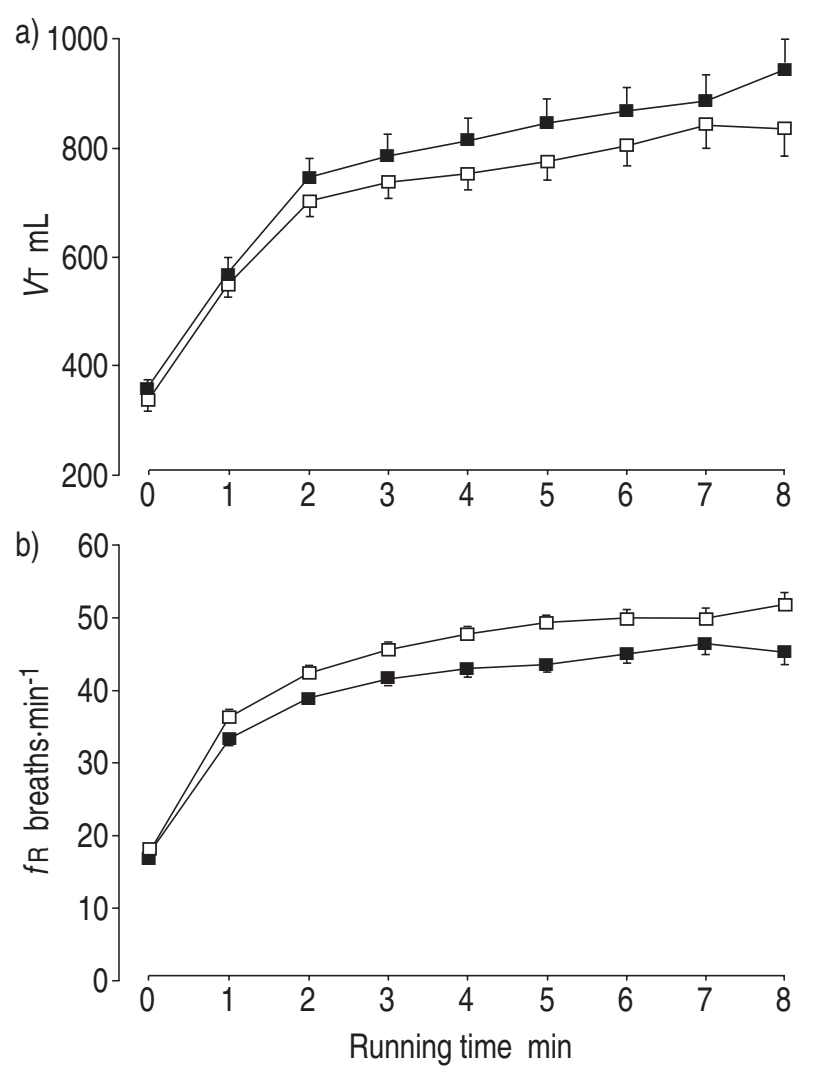

Fig. 2. - Time course of a) tidal volume $(V T)$; and b) respiratory frequency $(f R)$ during maximal exercise in asthmatic (- - ) and control ( $\square-$ ) children. $f \mathrm{R}$ was significantly lower (analysis of variance (ANOVA) $\mathrm{p}<0.001$ ) and $V \mathrm{~T}$ was significantly higher (ANOVA $\mathrm{p}<0.01)$ in asthmatics compared to controls. The data are expressed as mean \pm SEM.

\section{Relationship between pulmonary function and exercise performance}

A possible relationship between baseline pulmonary function and level of exercise performance was sought by Pearson's correlation coefficient. No significant correlation was found between pulmonary function (both baseline FEV1 and postexercise $\triangle \mathrm{FEV} 1)$ and $V^{\prime} \mathrm{O}_{2}$, max, $V^{\prime}$,max, AT, $V^{\prime}$,max/MVV and $\mathrm{O}_{2}$ pulse,max.

\section{Discussion}

In this study, we found that the level of exercise performance of children with controlled, mild-to-moderate asthma was not different from that of healthy age-matched controls. Asthmatic and control children showed comparable values of oxygen consumption and minute ventilation both at submaximal and maximal levels of exercise, indicating a similar aerobic work capacity. In addition, the anaerobic threshold and maximal oxygen pulse were the same in the two populations, indicating no aerobic or circulatory limitation for asthmatics. Furthermore, asthmatic children were able to achieve the same minute ventilation as controls by exhibiting a peculiar respiratory pattern during exercise, characterized by lower respiratory rates and higher tidal volumes. The most important factor affecting exercise tolerance was found to be the level of physical conditioning of the subjects.
The design of this study presents some features that should reduce biases in interpreting the results. Firstly, to our knowledge, this is the largest study on gas exchange during exercise in asthmatic children, and problems with statistical power were, thus, avoided. Secondly, the children were affected by mild-to-moderate asthma and, thus, were a homogeneous group, representative of the vast majority of the asthmatic population in the paediatric age group. Thirdly, the level of conditioning was regarded as a major factor for matching subjects, thus avoiding a frequent bias in comparison of asthmatics and healthy individuals. Lastly, the assessment of exercise tolerance and fitness was accomplished through an overall analysis of maximal indices of aerobic performance as well as the trends of the same parameters at different submaximal levels of exercise, as recently recommended when dealing with children [21].

In the present study, we found that, in asthmatic children, aerobic power, as indicated by maximal oxygen consumption $\left(V^{\prime} \mathrm{O}_{2}, \max \right)$ and anaerobic threshold (AT), was not different from that of healthy control children, showing that the availability and the utilization of oxygen by the exercising muscles was normal [18]. Further indices of exercise tolerance, such as maximal ventilation $\left(V^{\prime}\right.$ E,max $)$, dyspnoea index ( $\left.V^{\prime} \mathrm{E}, \max / \mathrm{MVV}\right)$ and maximal oxygen pulse $\left(\mathrm{O}_{2}\right.$ pulse,max $)$, were comparable between asthmatics and controls, suggesting that asthmatic children appear to have no greater ventilatory or circulatory limitation to their work capacity. Running time, and, consequently, maximal work rate, was slightly but not significantly higher in controls, a finding that could explain the higher maximal heart rate achieved by healthy children $(\mathrm{p}<0.001)$. The information regarding trends, i.e. submaximal responses, of $V^{\prime} \mathrm{O}_{2}, V^{\prime} \mathrm{E}, V^{\prime} \mathrm{E} / V^{\prime} \mathrm{O}_{2}$ provided a further confirmation to the above findings. They showed comparable response patterns to exercise stress for asthmatic and control children (figs. 1 and 2).

The data on gas exchange and ventilation during exercise in asthmatics have remained an issue of debate for many years. A number of studies of adults have found both comparable and reduced physical fitness in asthmatics with respect to healthy controls [2, 3, 22-24], and the relative importance both of disease severity and hypoactivity has continued to be debated. In the paediatric age group, most studies during the last 30 yrs have found that asthmatic children have lower work/aerobic capacity than healthy controls [6-10]. In their historical work, CROPP and TANAKAWA [8] described a typically higher $V^{\prime} \mathrm{E}$ and $V^{\prime} \mathrm{E} / V^{\prime} \mathrm{O}_{2}$ during exercise and a reduced $V^{\prime} \mathrm{O}_{2}$, max in asthmatics. However, it should be noticed that these studies were performed on small populations or on subjects with severe and acute asthma, so that the conclusions could not be extended to the majority of asthmatic children. It has been only a few years since the relationship between physical fitness and HLPA has been thoroughly investigated. GARFINKEL et al. [13] found that work capacity in 27 premedicated asthmatic adults with mild-to-moderate, stable asthma was related only to the amount of regular physical activity. Neither expiratory flow rates nor nonspecific bronchial hyperreactivity were shown to affect aerobic capacity. FINK et al. [14], comparing the response to exercise of asthmatic children premedicated with salbutamol with that of healthy children, found that only sedentary asthmatics had 
abnormal physical fitness, whilst asthmatic and control children had comparable gas exchange parameters when the degree of physical activity was the same.

Our data confirm the results of GARFINKEL et al. [13] and FINK et al. [14], showing the major role of physical conditioning in affecting physical performance in paediatric asthma. A careful matching of the subjects according to the HLPA, in addition to anthropometric features, was carried out. As for the two main groups (asthmatics and controls), there were no significant differences in exercise performance between asthmatic and control children within each of the three HLPA subgroups. On the other hand, both in asthmatics and controls, the level of physical fitness was significantly higher in the more conditioned children with respect to the less active subgroups (table 4). It should be emphasized that, if asthma is well-controlled, the level of physical conditioning is more important than the disease per se in determining the work capacity of the subject.

An interesting aspect of ventilatory pattern during exercise in asthma regards the different course of tidal volumes $(V \mathrm{~T})$ and respiratory rates $(f \mathrm{R})$ with respect to healthy children. Our data showed that asthmatic children had greater $V \mathrm{~T}$ along with lower $f \mathrm{R}$ with respect to controls at different steps of the run, while $V^{\prime} \mathrm{E}$ was comparable in the two groups. Different ventilatory response patterns have been found in the past [7,8]. Our results are similar to those of RAMONATXO et al. [10], who described, during the run, higher $V \mathrm{~T}$ and lower $f \mathrm{R}$ in a small group of asthmatic children. The authors suggest that this breathing pattern could avoid turbulences and a consequent increase in the work of breathing. It has recently been recognized that bronchoconstriction can also occur during exercise in asthmatics, apart from the evidence of EIA at the end of running [17, 25]. Thus, the ventilatory strategy observed in the present patients may be aimed to reduce the work of breathing. The results of our exercise test demonstrate that asthmatics, through their different respiratory pattern, were able to maintain efficient ventilation and gas exchange and to perform in the same way as healthy controls.

In the present population of asthmatic children, baseline pulmonary function showed no correlation with parameters of exercise performance. We were unable to demonstrate any correlation between baseline FEV 1 or postexercise $\triangle \mathrm{FEV} 1$ with $V^{\prime} \mathrm{O}_{2}, \max , V^{\prime} \mathrm{E}$,max, AT, $V^{\prime} \mathrm{E}$,max/ MVV and $\mathrm{O}_{2}$ pulse,max. A relationship between pulmonary function and exercise performance has been found by some authors [26] but not by others [8, 27, 28], probably due both to the low number of subjects analysed and the wide degree of disease severity. The present results are in agreement with the more recent literature on adult asthma, suggesting that the relationship between pulmonary function and aerobic capacity is not linear and cannot be predicted [2, 13, 28, 29]. A ventilatory limitation to physical capacity may be present only in severe asthma [28], where more complex mechanisms are involved in the pathophysiology of the disease, but is very unlikely in children with controlled, mild-tomoderate asthma. In this sense, the regular use of inhaled steroids, as recommended by the more recent guidelines for asthma management [15], could indirectly improve the physical fitness of asthmatic children owing to a better control of the disease.
In conclusion, our data show that children with mildto-moderate asthma and good control of their disease are as fit as healthy peers in performing maximal exercise testing. In this population, the major factor affecting the level of exercise tolerance seems to be the level of habitual physical activity. The resting pulmonary function and the degree of bronchospasm induced by exercise are not correlated to aerobic and ventilatory capacity. The only difference found regards the breathing pattern of asthmatics which, during exercise, presents greater tidal volumes and lower respiratory rates compared to healthy controls. It is now recognized that there is no reason to limit daily physical activity as part of a normal lifestyle in well-controlled asthma. We believe that the results of this study provide solid evidence for reassuring physicians on the work capacity of asthmatics and for encouraging asthmatic children to take part in sporting activities.

Acknowledgements: The enthusiastic assistance of G.P. Magagnin during the exercise tests is gratefully acknowledged. The authors thank W. Mazza, director of a public school in Padova, for kind co-operation.

\section{References}

1. Cooper DM. Pulmonary function assessment in the laboratory during exercise. In: Kendig's Disorders of the Respiratory Tract in Children. Philadelphia, W.B. Saunders, 1990; pp. 154-157.

2. Clark CJ, Cochrane LM. Assessment of work performance in asthma for determination of cardiorespiratory fitness and training capacity. Thorax 1988; 43: 745-749.

3. Feisal KA, Fuleihan FJD. Pulmonary gas exchange during exercise in young asthmatic patients. Thorax 1979; 34: 393-396.

4. Nixon PA, Orenstein DM. Exercise testing in children. Pediatr Pulmonol 1988; 5: 107-122.

5. Varray AL, Mercier JG, Terral CM, Préfaut CG. Individualized aerobic and high intensity training for asthmatic children in an exercise readaptation program. Chest 1991; 99: 579-586.

6. Beaudry PH, Wise MB, Seely JE. Respiratory gas exchange at rest and during exercise in normal and asthmatic children. Am Rev Respir Dis 1967; 95: 248-254.

7. Vavra J, Macek M, Spicak V. La capacité de travail chez les enfants asthmatiques. Rev Pediatr 1969; 5: 3-7.

8. Cropp GJA, Tanakawa N. Cardiorespiratory adaptations of normal and asthmatic children to exercise. In: Dempsey JA, Reed CE, eds. Muscular Exercise and the Lung. Madison, University of Wisconsin Press, 1977; pp. 265-278.

9. Hedlin G, Graff-Lonnevig V, Freyschuss U. Working capacity and pulmonary gas exchange in children with exercise-induced asthma. Acta Paediatr Scand 1986; 75: 947-954.

10. Ramonatxo M, Amsalem FA, Mercier JG, Jean R, Préfaut CG. Ventilatory control during exercise in children with mild or moderate asthma. Med Sci Sports Exerc 1989; 21: 11-17.

11. Bar-Or O. In: Pediatric Sports Medicine for the Pratictioner. New York, Springer-Verlag New York Inc., 1983; pp. 101-104.

12. Boner AL, Spezia E, Piovesan P, Chiocca E, Maiocchi $\mathrm{G}$. Inhaled formoterol in the prevention of exerciseinduced bronchoconstriction in asthmatic children. Am J Respir Crit Care Med 1994; 149: 935-939.

13. Garfinkel SK, Kesten S, Chapman KR, Rebuck AS. 
Physiologic and nonphysiologic determinants of aerobic fitness in mild-to-moderate asthma. Am Rev Respir Dis 1992; 145: 741-745.

14. Fink G, Kaye C, Blau H, Spitzer SA. Assessment of exercise capacity in asthmatic children with various degrees of activity. Pediatr Pulmonol 1993; 15: 41-43.

15. NHLBI/WHO Working Report. Global strategy for asthma management and prevention. National Institutes of Health. NHLBI Publication No. 95-3659, January 1995.

16. Polgar G, Promadhat V. Pulmonary function testing in children: techniques and standards. Philadelphia, W.B. Saunders Co., 1974.

17. Baraldi E, Santuz P, Magagnin G, Filippone M, Zacchello F. Effects of disodium cromoglycate on ventilation and gas exchange during exercise in asthmatic children with a postexertion FEV1 fall less than 15\%. Chest 1994; 106: $1083-1088$.

18. Wasserman K, Hansen JE, Sue DY, Whipp BJ. Principles of exercise testing and interpretation. Philadelphia, Lea \& Febiger, 1987; pp. 27-86.

19. Zanconato S, Baraldi E, Santuz P, Magagnin G, Zacchello F. Effect of inhaled disodium cromoglycate and albuterol on energy cost of running in asthmatic children. Pediatr Pulmonol 1990; 8: 240-244.

20. Santuz P, Baraldi E, Zaramella P, Filippone M, Zacchello F. Factors limiting exercise performance in long-term survivors of bronchopulmonary dysplasia. Am J Respir Crit Care Med 1995; 152: 1284-1289.

21. Cooper DM. Rethinking exercise testing in children: a challenge. Am J Respir Crit Care Med 1995; 152: 1154-1157.
22. Ingemann-Hansen T, Bundgaard A, Halkjaer-Kristensen J, Sigaard-Andersen J, Weeke B. Maximal oxygen consumption rate in patients with bronchial asthma: the effect of $\beta_{2}$-adrenoreceptor stimulation. Scand J Clin Lab Invest 1980; 40: 99-104.

23. Friberg S, Bevegard S, Graff-Lonnevig V, Hallbaeck I. Asthma from childhood to adulthood: a follow-up study of 20 subjects with special reference to work capacity and pulmonary gas exchange. J Allergy Clin Immunol 1989; 84: 183-190.

24. Varray A, Préfaut C. Importance of physical exercise training in asthmatics. J Asthma 1992; 29: 229-234.

25. Beck KC, Offord KP, Scanlon PD. Bronchoconstriction occurring during exercise in asthmatic subjects. Am J Respir Crit Care Med 1994; 149: 352-357.

26. Katz RM, Whipp BJ, Heimlich EM, Wasserman K. Exercise-induced bronchospasm, ventilation, and blood gases in asthmatic children. J Allergy 1971; 47: 148158.

27. Bevegard S, Eriksson BO, Graff-Lonevig V, Kraepelien $\mathrm{S}$, Saltin B. Respiratory function, cardiovascular dimensions and work capacity in boys with bronchial asthma. Acta Paediatr Scand 1976; 65: 289-296.

28. Lewis MJ, Belman MJ, Monn SA, Elashoff JD, Koerner SK. The relationship between oxygen consumption and work rate in patients with airflow obstruction. Chest 1994; 106: 366-372.

29. Lorusso TJ, Belman MJ, Elashoff JD, Koerner SK. Prediction of maximal exercise capacity in obstructive and restrictive pulmonary disease. Chest 1993; 104: $1748-1754$ 